\title{
Examining Factors Driving Changes in Food Choice Behavior of Rural Households in Adola Rede District, East Guji Zone, Ethiopia
}

\author{
Korji Dembi $^{1}(\mathrm{MSc}) \quad$ Seyoum Chanyalew ${ }^{2}(\mathrm{PhD}) \quad$ Gezahegn Muluken ${ }^{2}(\mathrm{PhD})$ \\ 1 Bore Agricultural Research center, Oromia Agricultural research Institute (OARI), Finfine, Ethiopia, \\ P.O.Box, 904 \\ 2 Department of rural Development and Agricultural Extension, Haramaya University, Dire Dawa, Ethiopia
}

\begin{abstract}
Improving nutrition across the life course from conception through adulthood is essential for the long- term wellbeing of families and communities and for successful economic and social advancement. A key challenge to achieving sustainable improvement in adequate food choice behavior is the limited knowledge about drivers of food choice particularly among the poor in LMIC, of which Ethiopia is one. Therefore the objective of this study is to identify factors influencing food choice behavior of rural households in Adola Rede district. Multi-stage sampling procedures were employed. Probability sampling to size and random sampling techniques were used to determine study sits, sample respondents from each study sits and draw sample respondents respectively. Survey data was collected from 150 sample respondents using interview schedule. Focus group discussions were also conducted. Descriptive statistics and ordered logit model were employed. Food choice behaviors of the rural households were categorized depending on Food Consumption Score used widely by World Food Program. Among 13 variables used in model, dependency ratio, total land holding, number of livestock owned, access to credit, education and agro- ecology were significantly related to the rural households' food choice behavior. The food choice behaviors of the household respondents were $30 \%$ poor, $45 \%$ borderline and $25 \%$ adequate food choice behavior. An overwhelmingly, three- fourth of the respondents were found to be inappropriate food choice behavior. Therefore, local government and nongovernmental organizations should give emphasis for improving food choice behavior through continuous training, coaching, asset building and capital mobilization and improving access to different service provider institutions.
\end{abstract}

Keywords: Ethiopia; drivers; food consumption score; food choice; rural households; ordered logit model

DOI: $10.7176 / \mathrm{FSQM} / 101-02$

Publication date:September $30^{\text {th }} 2020$

\section{INTRODUCTION}

According to the 1996 World Food Summit, "food security at the individual, household, national, regional and global levels is achieved when all people, at all times, have physical and economic access to sufficient, safe and nutritious food to meet their dietary needs and food preferences for an active and healthy life" (FAO, 1996). This definition broadens the initial focus of the 1974 World Food Summit (United Nations 1974) on the volume and stability of food supplies, by including secured access for all people, especially the most vulnerable, to available supplies, and by incorporating food safety and nutritional balance. The 1996 definition also reflects concerns about food composition and nutrient requirements for an active and healthy life.

Many people were affected by vitamin and mineral deficiencies - one out of three in developing countries. At the same time, 1.5 billion adults were overweight in 2008; this is due to inappropriate food consumption behavior including over 200 million obese men and nearly 300 million obese women (WHO, 2011). In addition, a growing number of low and middle-income countries are facing a double burden of malnutrition, i.e., the persistence of under-nutrition, notably among children, along with a rapid rise in overweight and obesity, and diet-related chronic diseases (FAO, 2006; IFPRI, 2014).

Food choice behavior of the individual is a complex process influenced by a variety of determinants related to the food, to the external environment and to the individual which interact to produce food choice (Murcott, 1998). Socioeconomic and individual resources determined by the broader political and economic environment which can play an important role in determining food choice and eating behavior (Drewnowski, 2004).

Socio-cultural beliefs and customs have a significant influence on family nutritional well-being. In terms of food choice, some foods are more prized than others and a meal is never considered complete until they are included and enriched with additional food groups such as fats/ oils, fruits, vegetables etc. (RK Oniang'o et al., 2003). The prevalence of under nutrition in the study area, and the kinds of food available to address under nutrition but could not due issues associated with food choice behavior like social, culture, institution and environment besides socio- economic and demographic characteristics. Thus this study intended to search further and fill knowledge gaps based on adequate data and sufficient methods of analysis to expand and update our understanding 


\subsubsection{Specific objective}

The specific objective of the study is:

1. To identify socioeconomic and demographic factors influencing food choice behavior of rural households.

\subsubsection{Conceptual Framework}

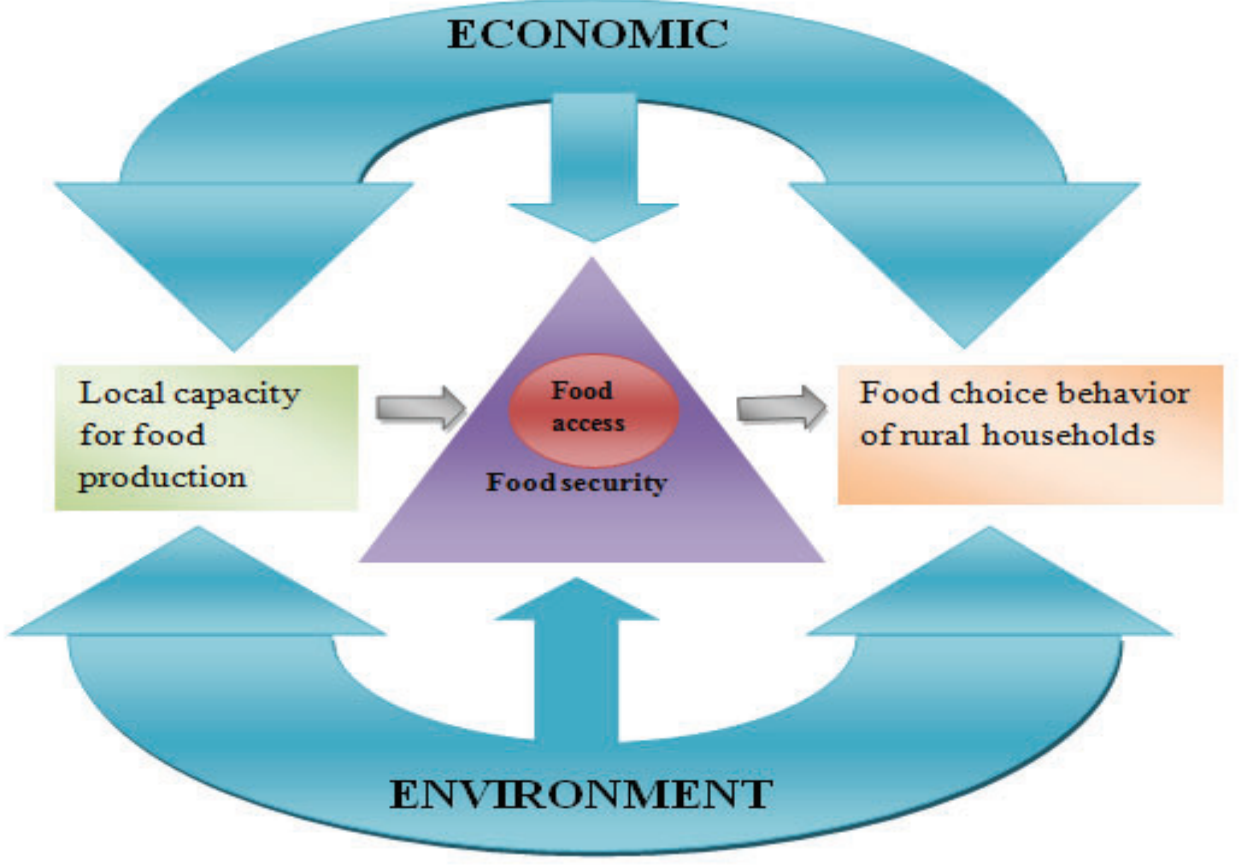

Fig.1. Conceptual framework

Source: Adapted from Stubblefield et al. (2010); California Center for Rural Policy (CCRP).

Local capacity for food can be defined as the ability of the household in local area to produce, import, process and choose food for consumption. There may be certain local products that are produced on a fairly large scale (e.g. maze, Teff, wheat etc.). There may also be small community and individual household gardens that serve to provide food at a smaller scale. In the model, the local capacity for food directly impacts food security and as a result, food access. For example, if you have a place where there is limited local capacity for food, such as occurs in a more urban environment, the food security of the households in that region would be negatively impacted.

Food access and food security: Food access is defined food as people's ability to access healthy food, including not only the availability of healthy food, but its affordability and cultural appropriateness to the individual. Food security is defined as the access by all people at all times to enough food for an active and healthy lifestyle. Food security and food access are two intertwined concepts. This model assumes that food access is a major component of food security, which is why the circle (food access) is set inside the triangle (food security) in the model. Food security is a macro-level concept, and food access is an important piece of that larger concept. The definition of food security implies that when food security is strong, so is food access and hence food choice.

Food choice behavior is defined as the general consumption habit of the households. It takes a broad view of concept and defined as consisting of the physical, social, and economic well-being of the rural households. Ultimately, many factors affect rural households' food choice behavior. This model indicates that the economy, the environment and food security all impact food choice behavior. If a households' region has a solid economy and fertile environment that is conducive to diverse agricultural production, chances are the food security of the households would also be good. Households' food consumption habit would also be expected to be good given the influence of the positive economy, environment and food security and food access.

The economy and the environment are two overarching contextual factors that influence everything in the model. The economy can be described as the general flow of commerce in an area. This consists of the ebb and flow of production and distribution of goods and services and would include things like local jobs, retail establishments, entrepreneurial opportunities and lending institutions. In the model economy impacts local capacity for food, for example rural households' access to capital, marketing opportunities and production choices. The economy of the households, including the demographic characteristics of the households as human capital (skills, knowledge, the ability to work and good health) is the important livelihood assets influences rural people's general food security and their access to food. The economy influences things like an individual's purchasing power as well as the types of food available to a particular household. Overall, higher income households are going to have a greater selection of diverse healthy and nutritious foods than poorer households along with a greater 
ability to purchase such foods. The other major contextual factor that influences the entire model is the environment. The environment consists of the physical context of the place, including aspects such as: how rural or remote is the rural households' community? What types of crops grow best in this region? What is the climate like? What is the topography? What prime soils exist in the region?

The type of food produced in a particular households' region would ultimately be affected by factors such as the climate, topography and soil type. The model highlights the role of place through the environment variable. And patterns of human activity at various scales within the physical environment which incorporates social, cultural and institutional considerations also manage food consumption/choice behavior of rural households.

\section{METHODOLOGY}

\subsection{Description of the Study Area}

Adola Rede district is located in southern part of Oromia, Ethiopia, at a distance of 468km from Addis Ababa. Astronomically the district is located between 5 $44^{\prime} 10^{\prime \prime}-6^{\circ} 12^{\prime} 38^{\prime \prime}$ Northing latitudes and $38^{\circ} 45^{\prime} 10^{\prime \prime}-39^{\circ} 12^{\prime} 37^{\prime \prime}$ Easting longitudes. It shares boundary with Ana Sora in the North-West, Wadera in the South- East and Odo Shakiso in the south and Girja in the North- East directions. It has the total area of about $1401 \mathrm{~km}^{2}$. Most of the earth surface of the district is ups and downs of the land surface with an elevation ranging from 1350 meters up to 2340 meters. Like in many parts of Ethiopia, the farming system in Adola Rede is still traditional with oxen and yolk (animal's power), and labour as the major means of production during land preparation, planting and harvesting as well as post harvest process. Rain-fed agriculture is a common practice for many farm households in this district. However, a semi-nomadic economic activity is also practiced as a means of livelihood by some of its residents. This district has 29 rural kebeles and two urban kebeles. The farmers of this district produce both in meher and belg seasons. They produce cereals such as teff, wheat, barley and maize, pulses such as haricot bean, and others such as fruits and vegetables. Overall, wheat, maize and teff are the major crops cultivated by the farmers in this study area. They also engaged in the production of coffee as means of livelihood. Furthermore, this district has a potential for livestock production which is witnessed by farmers ownership large number of livestock.

\subsection{Sample Size and Sampling Techniques}

Adola Rede district has 29 rural kebeles and two urban kebeles. It has three agro-ecological zones namely: dega, woina dega and kola. In this study, samples of 150 rural households were taken from this district by using the formula provided by (Yemane, 1967, cited in Udayakumara et al., 2010).

$\begin{array}{cc}\mathrm{n}=\frac{\mathrm{N}}{1+\mathrm{N}}(\mathrm{e})^{2} & \begin{array}{c}\text { Where: } \mathrm{n}=\text { sample size } \\ \mathrm{N}=\text { Total population }\end{array} \\ & \mathrm{e}=\text { Level of Precision or Margin of error } \\ & 92 \% \text { level of precision were used to determine }\end{array}$

In order to select these respondents and study sites, a. multi-stage sampling techniques were employed. First, 29 kebeles administrations (KAs) in Adola Rede district were stratified in to three agro-ecologies with 15 KA low land (kola), $11 \mathrm{KAs}$ midland (woina dega) and $3 \mathrm{KAs}$ highland (dega). Numbers of study sites were also determined by using probability proportional to size (PPS) techniques. Second, simple random sampling (SRS) techniques were used to draw sample KAs from each stratum and probability proportional to size were used to determine sample households for the selected KAs. Third, simple random sampling (SRS) techniques were used to draw sample households for the respective study KAs using comprehensive sample frame of respective KAs. Accordingly, 3, 2 and 1 KAs were determined from the lowland, midland and highland respectively and 150 sample households were drawn. 


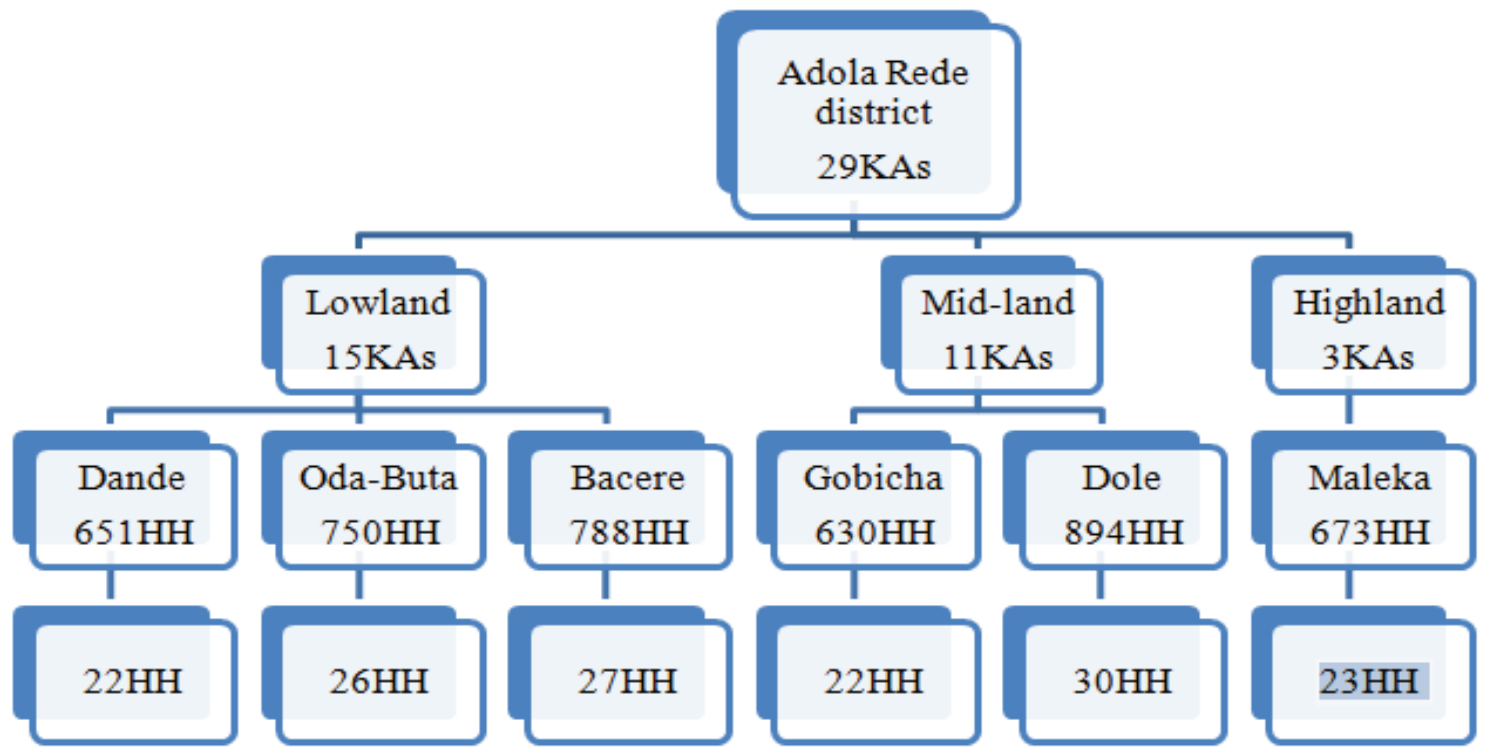

Fig.2. sampling techniques

\subsection{Types, Sources and Method of Data Collection}

This study was conducted in Adola Rede district to study factors driving changes in food choice behavior of rural households. The study was focused on rural households' food choice preferences for different eight food items aggregated from FAO food balance sheet and the factors influencing their decision for consumption. To undertake this study the primary data was used. The primary data was collected from the rural households of this district using a semi- structured survey questionnaire and interview with key informants and focus group discussions. The person responsible for meal preparation was included apart from the household head to gather information on household food consumption. The survey questionnaire was prepared in English and translated to local language ('Afan Oromo') so as to get precise information from the households since this language is used by the residents in this district.

\subsection{Data Analysis}

For the analysis of the data collected from the sample respondents both descriptive statistics and econometric analysis methods were used. The ordered logit model was used to identify factors driving changes in food choice behavior of rural households. Statistical Package for Social Science (SPSS) version 16 and STATA version 12 were used as tools for data entry and analysis.

\subsubsection{Descriptive statistics}

The 7 days diet recall period was used in order to capture household's food choice behavior rather than 24 hours recall period, thereby reducing the risk of selection bias (Horjus, 2010). The food choice behavior of the rural households was categorized depending on Food Consumption Score used widely by World Food Program (WFP, 2008) to indicate adequate or inadequate food consumption behavior for the households constructed using FCS by multiplying the frequency of each food group by its weight which gives 'weighted food group values. The Food Consumption Score was divided into three categories. A Food Consumption Score less than or equal to 21 was classified as poor food choice behavior; FCS from 21.5 to 35 as borderline food choice behavior; and a FCS more than 35 as adequate food choice behavior, based on World Food Program (WFP, 2008). The FCS was calculated by using the following steps with simple hand calculation:

I).Using standard 7-days food frequency data, group all the food items from the comprehensive FAO food balance sheet into eight specific food groups; these are: 1) starches, 2) pulses, 3) vegetables, 4) meat, 5) dairy, 6) fruits, 7) fats/oil and 8) sweets;

II).Sum all the consumption frequencies of food items of the same group, and recode the value of each group above 7 as 7 ;

III).Multiply the values obtained for each food group by its weight and create new weighted food group scores; IV).Sum the weighed food group scores, thus creating the food consumption score (FCS) and;

V).Using the appropriate thresholds and recode the variable food consumption score, from a continuous variable to a categorical variable. 


\subsubsection{Econometric Model}

Based on the categorical nature of the dependent variable and data required to achieve the objective of the current study ordered logit model was employed. The ordered logit model was used to analysis factors affecting rural households' food choice behavior. The response variable had more than two outcomes and these outcomes were ordinal in nature; that is, they could not be expressed on interval scale. These responses were coded as $0,1,2$, showing a clear ranking among the categories, but the difference among adjacent categories could not treated as the same (Gujarati, 2004). Responses like these with ordered categories cannot be easily modeled with classical regression. Ordinary linear regression is inappropriate because of the non-interval nature of the dependent variablethe spacing of the outcome choices cannot be assumed to be uniform. Ordinal logit and probit models have been widely used for analyzing such data (Liao, 1994).

The logit and probit model used to estimate probabilities that lie between 0 and 1. Logit and probit model give qualitative similar results. In most applications they are quite similar, the main difference being that the logistic distribution has slightly fatter tails. That is to say, the conditional probability approach zero or one at a lower rate in logit than in probit. Therefore there is no compelling reason to choose one over the other. But for comparative mathematical simplicity of logit model (Gujarati, 1995; 2004).

The household food choice behavior, which is the dependent variable for the logit analysis is a polytomous dependent variable and categorized as:

- Level: 1 Adequate or acceptable food choice behavior (Y=2): This refers to households whose FCS is more than 35 over the reference period.

- Level 2: Borderline food choice behavior $(\mathrm{Y}=1)$ : This refers to households whose FCS is 21.5 to 35 over the reference period.

- Level 3: Poor food choice behavior $(\mathrm{Y}=0)$ : This refers to households whose FCS is less or equal to 21. Following Green (2000) and Liao (1994) the mathematical specifications of ordered logit model is given as follows

$$
y *=\sum_{k=1}^{k} B_{k} x_{k}+\epsilon
$$

$\mathrm{y}^{*}=$ is unobserved and thus can be thought of as the underlying tendency of an observed phenomenon.

= we assume it follows a certain symmetric distribution with zero mean such as normal or logistic distribution. What we do observe is:

$$
\begin{aligned}
& y=1 \text { if } y^{*} \leq \mu_{1} \\
& y=2 \text { if } \mu_{1}<y^{*} \leq \mu_{2} . \\
& y=j \text { if } \mu_{j-1}<y^{*}
\end{aligned}
$$

Where $\mathrm{y}$ is observed in $j$ number of ordered categories, " $\mu$ "s are unknown threshold parameters separating the adjacent categories to be estimated with " $\beta$ "s.

The general form for the probability that the observed y falls into category $\mathrm{j}$ and the " $\mu$ "s and the " $\beta$ "s are to be estimated with an ordinal logit model is

$$
\operatorname{Prob}(y=j)=1-L\left(\mu_{j-1}-\sum_{i}^{k} B_{k} X_{k}\right)
$$

Where, $L=$ represents cumulative logistic distribution.

According to Gujarati (1995) there are various indicators of multicollinearity and no single diagnosis will give as a complete handle over the collinearity problem. To check for existence of multicollinearity between the hypothesized explanatory variables, Variance Inflation Factor (VIF) was employed before estimating the logit model. Since, it is important to eliminate the effect of multicollinearity on parameter estimation (Gujarati, 1995, 2004). Thus each selected continuous variable will regress on all other continuous explanatory variables, by constructing a coefficient of determination $\left(\mathrm{R}_{\mathrm{j}}{ }^{2}\right)$ for each individual case. A popular applied measure of multicollinearity associated with VIF is defined as:

$$
V I F(X j)=\left(\frac{1}{1-R j^{2}}\right)
$$

Where, $\mathrm{X}_{\mathrm{j}}=$ the $\mathrm{j}^{\text {th }}$ quantitative explanatory variable regressed on the other quantitative explanatory variables. $\mathrm{Rj}^{2}=$ coefficient of determination when the variable $X j$ is regressed on the remaining explanatory variables. If the approximate linear relationship exists among explanatory variables, a large value of $\left(\mathrm{Rj}^{2}\right)$ would appear in 
at least one of the test regressions. A rise the value of $\left(\mathrm{Rj}^{2}\right)$ would also leads to increase in the variances and standard error. As a rule of thumb, if the value of VIF exceeds 10 that variable is said to be highly collinear and it could be concluded that there is a multicollinearity problem (Gujarati, 1995).

Moreover, an interaction between qualitative variables (discrete explanatory) could also lead to a problem of multicollinearity or strong association. To detect the interaction or association of discrete variables coefficient of contingency (CC) would also be computed. The criteria used to judge multicollinearity problem is; if CC is greater than 0.75 , the variables are said to be collinear (Gujarati, 1995).

The $\mathrm{CC}$ is computed as follows:

$$
\mathrm{CC}=\sqrt{\frac{x^{2}}{N+x^{2}}}
$$

Where, $\mathrm{CC}=$ coefficient of Contingency; $\mathrm{N}=$ Total sample size; $X^{2}=$ Chi-square test value The value of coefficient of contingency ranges between -1 and 1 , where -1 indicates negative association between the variables and 1 indicates existence of high degree (perfect) association between the variables.

\section{RESULTS AND DISCUSSION}

\subsection{Food Choice Behavior of the Respondents}

\subsubsection{Food choice behavior of the respondents}

The food choice behavior of the rural households was categorized depending on Food Consumption Score used widely by World Food Program (WFP, 2008) to indicate adequate or inadequate dietary diversity or food choice behavior for the households. FCS was calculated over a reference time period of 7 days and based on a list of 8 food groups from FAO food balance sheet. This was done using the food frequency questions that how often have the eight food groups been served in households over the past 7 days diet recall period. Different weights, ranging from 0.5 to 4, were applied to the eight food groups according to their nutrient density (Vaitla et al., 2012; WFP, 2008).

The consumption frequencies were summed for each food group (with an upper limit of 7). FCS was computed by multiplying frequencies and weights for each food group and summing values over the 8 groups (theoretical range $=0$ - 112). The Food Consumption Score was divided into three categories. A Food Consumption Score less than or equal to 21 was classified as poor food choice behavior; FCS from 21.5 to 35 as borderline food choice behavior; and a FCS more than 35 as adequate food choice behavior. This is done by simple hand calculation.

The average Food Consumption Score of the sample respondents was 34.27. The Food Consumption Score of the sample respondents ranges from 19.5 to 54. Following WFP, (2008), out of 150 respondents interviewed, one-fourth of the total sampled rural households fell into appropriate food choice behavior category. $45 \%$ and $30 \%$ of the household respondents fell into borderline and poor food choice behaviors categories respectively. Rural households, who fell into borderline and poor food choice categories, were referred as food insecure.

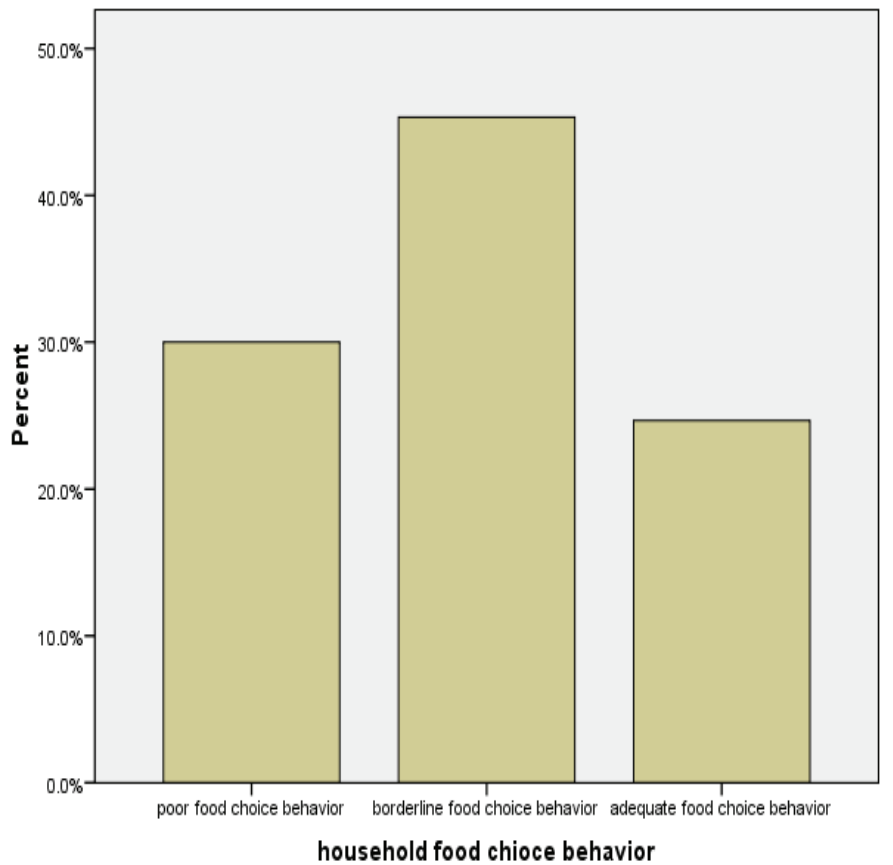

Fig.3. Food choice behavior of the respondents.

Source: own survey 2018 


\subsection{Result of Ordered logit Model}

A total of 14 potential explanatory variables were selected on the basis of theoretical explanations, personal observations and association among the variables and checked for muticollinarity problem before running the final regression; Sex and marital status had multicollinarity problem. Therefore, all were retained for ordered logit analysis except marital status. Among the factors that had a significant influence, education level, total farm land, number of livestock ownership, access to credit service and agro- ecology were positive influence, whereas dependency ratio was negative influence on the food choice behavior of the rural households.

Table 1. Determinants of household food choice behavior (FCB).

\begin{tabular}{|c|c|c|c|c|c|c|c|}
\hline HHFCBR & Coef. & Std. Err. & $\mathrm{Z}$ & $\mathrm{P}>|\mathrm{z}|$ & $\mathrm{dy} / \mathrm{dx}(\mathrm{Y}=2)$ & $\mathrm{dy} / \mathrm{dx}(\mathrm{Y}=1)$ & $\mathrm{dy} / \mathrm{dx}(\mathrm{Y}=0)$ \\
\hline AGEHH & .0517 & .0318 & 1.62 & 0.104 & .0018 & -.0003 & -.0014 \\
\hline SEXHH & -.1792 & 1.3894 & -0.13 & 0.897 & -.0067 & .0019 & .0048 \\
\hline HHSIZE & -.1337 & .2317 & -0.58 & 0.564 & -.0046 & .0007 & .0038 \\
\hline DEPRATIO & -5.4353 & 1.7134 & -3.17 & $0.002 * * *$ & -.1898 & .0322 & .1575 \\
\hline TOTFLAND & .3473 & .1568 & 2.21 & $0.027 * *$ & .0121 & -.0020 & -.0100 \\
\hline LIVSTOCK & .6840 & .1258 & 5.44 & $0.000 * * *$ & .0238 & -.0040 & -.0198 \\
\hline DCMARKET & .3023 & .3416 & 0.88 & 0.376 & .0105 & -.0017 & -.0087 \\
\hline OFNFEMPL & -1.4248 & 1.2890 & -1.11 & 0.269 & -.0285 & -.0517 & .0802 \\
\hline ACREDIT & 1.1440 & .6601 & 1.73 & $0.083^{*}$ & .0587 & -.0345 & -.0242 \\
\hline ACCEXTN & -.0745 & 1.2745 & -0.06 & 0.953 & -.0026 & .0005 & .0020 \\
\hline EDULEVEL1 & -10.9459 & 2.0259 & -5.40 & $0.000 * * *$ & -.0884 & -.8982 & .9867 \\
\hline EDULEVEL2 & -8.9983 & 1.6036 & -5.61 & $0.000 * * *$ & -.8971 & .3824 & .5146 \\
\hline EDULEVEL3 & -6.0911 & 1.4372 & -4.24 & $0.000 * * *$ & -.1124 & -.6795 & .7920 \\
\hline SOILFRTY1 & -1.1564 & .8388 & -1.38 & 0.168 & -.0275 & -.0255 & .0531 \\
\hline SOILFRTY2 & .6243 & .5895 & 1.06 & 0.290 & .0252 & -.0092 & -.0159 \\
\hline AEZ1 & .6851 & .9860 & 0.69 & 0.487 & .0301 & -.0140 & -.0161 \\
\hline AEZ2 & 1.8942 & .7351 & 2.58 & $0.010 * *$ & .0956 & -.0483 & -.0472 \\
\hline cut1 & -5.8342 & 3.0115 & & & & & \\
\hline cut2 & .9266 & 2.8199 & & & & & \\
\hline No of obs. & 150 & & & & & & \\
\hline LR $\operatorname{chi} 2(17)$ & 186.74 & & & & & & \\
\hline Prob. $>$ chi 2 & 0.0000 & & & & & & \\
\hline Pseudo R2 & 0.5844 & & & & & & \\
\hline Log likelihood & -66.3955 & & & & & & \\
\hline
\end{tabular}

Note: $* * *$ and $* * *=$ Significant at $10 \%, 5 \%$ and $1 \%$, respectively.

Source: model output.

Dependency ratio (DEPRATIO) has negatively and significantly affects the food choice behavior of the rural households at less than 1\% significance level. This means that a unit increases in dependency ratio increases the likelihood of respondents falling into borderline and poor food choice behavior categories by $3.22 \%$ and $15.75 \%$ respectively While the likelihood of respondents falling into adequate food choice behavior category decreases by $18.89 \%$. Rural households with large family size, having children of non-productive age, could face the probability of poor food choice behavior because of high dependency ratio than farm households with large family size whose age composition ranges between 15- 64. The probable reason for this could be farming activities in the rural areas need intensive family labor and the working age population supports not only themselves, but also additional dependent persons as the existence of large number of children under age of 15 and old age of 65 and above in the family increases. Therefore, this agrees with the expected that household size with high dependency ratio had role to play in affecting the probability of households to become poor food choice behavior since they have many mouths to feed with relatively few labor force. This result is supported by response of respondents during focus group discussion which indicate that they face labor shortage to carry out their livelihood activities when the dependent family members existing.

Total farm land holding (FARMLAND) has positively and significantly influenced the food choice behavior of rural households at less than 5\% significance level. This means that a unit increase in total land holding increases the likelihood of respondents falling into adequate food choice behavior category by $1.21 \%$, while the likelihood of respondents falling into borderline and poor food choice behavior categories decreases by $0.2 \%$ and $1 \%$ respectively. This indicates that as total land owned by respondents increases, the capability of the households to cultivate a varieties of edible crops also increases and it would enhance the capacity of the household food security as well. This result is in line with Drewnowski (2004) that stated socioeconomic and individual resources, determined by the broader political and economic environment, which can play an important role in determining food choice and eating behavior. And with Christine et al. (2014) that stated Ownership of agricultural land is positively associated with food security status of the rural households. 
Livestock owned (TLU) has a positive and significant effect on the food choice behavior of rural households at less than $1 \%$ significance level. This means that a unit increases in TLU the likelihood of respondents falling into adequate food choice behavior category increases by $2.38 \%$, while the likelihood of respondents falling into borderline and poor food choice behavior categories decreases by $0.4 \%$ and $1.98 \%$ respectively. This indicated that household with larger TLU can have larger number of oxen to plough their land timely and sufficiently which help to produce better quality, larger amount and diversified edible crops. On top of this, they can have a better financial position to purchase some food commodities that are not available in their home as it was summarized from the focus group discussions. Moreover, Households with larger livestock size produce more milk, milk products and meat for direct consumption. A closer look at focus group discussions indicated that the contribution of livestock to food availability includes manure and income from sales of livestock and livestock products, which are often used for purchase of food grains during times of food shortage and livestock sale is also used as the major copping strategy during famine and seasonal food shortage in the study area.

Access to credit service (CREDIT) has a positive and significant effect on the food choice behavior of rural households at less than $10 \%$. This means that when the response of the respondents goes from non access to access of credit service, the likelihood of the respondents falling into adequate food choice behavior category increases by $5.87 \%$, while the likelihood of respondents falling into borderline and poor food choice behavior categories decrease by $3.45 \%$ and $2.42 \%$ respectively This result proved that credit is the impact factor since it can solve financial problems of rural households; purchase agricultural inputs, boost the production and productivity and therefore adjust food consumption behavior.

Analysis result of ordered logit model revealed that education level (EDULEVEL) of the household head has positively and significantly affect food choice behavior of the rural households at less than $1 \%$ significant level. This means that when education level of the rural households goes from grade1-grade4 to illiterate the likelihood of the respondents falling into adequate and borderline food choice behavior category decreases $8.84 \%$ and $89.82 \%$ respectively but the likelihood of falling into poor food choice behavior categories increases by $98.67 \%$. When education level of the rural households goes from grade5- grade8 to grade1- grade4, the likelihood of the respondents falling into adequate food choice behavior category decreases by $89.71 \%$ but the likelihood of falling into borderline and poor food choice behavior categories increases by $38.24 \%$ and $51.46 \%$ respectively. And when education level of the rural households goes from grade 9 and above to grade5-grade8, the likelihood of the respondents falling into adequate and borderline food choice behavior categories decreases by $11.24 \%$ and $67.97 \%$ respectively but the likelihood of falling into poor food choice behavior category increases by $79.20 \%$. This implies that the food choice behavior of educated rural households were better than uneducated rural households. This is because the literate households are exposed to information regarding nutritionally dense foods and meal preparation and consumption and storage as well from outside and impart this information to the household members who are responsible for meal preparation and the literate head of the family is more likely to diversify commodities for consumption. This result is in consistent with Kearney et al. (2000) which indicate that the level of education can influence dietary behavior during adulthood. And in contrast with De Almeida et al. (1997) that stated nutrition knowledge and good dietary habits are not strongly correlated. This is because knowledge about health does not lead to direct action when individuals are unsure how to apply their knowledge. Furthermore, information disseminated on nutrition comes from a variety of sources and is viewed as conflicting or is mistrusted, which discourages motivation to change.

Agro-ecology (AEZ) has a positive and significant effect on the food choice behavior of rural households at less than $5 \%$. This means that the likelihood of the respondents falling into adequate food choice behavior category increases by $9.56 \%$, when the response of the respondents goes from both lowland (AEZ1) and highland (AEZ3) agro- ecologies to mid-land (AEZ2) agro- ecology, while the likelihood of respondents falling into borderline and poor food choice behavior categories decrease by $4.83 \%$ and $4.72 \%$ respectively. This shows that midland agroecologies of the study area are better off than highland and low land agro-ecologies. This result is supported by Focus Group Discussions that summarized highland parts of the study area usually consume a vegetable food groups like local cabbage,' inset' and milk and lowland agro- ecologies of the study area usually consume foods made from maize, local cabbage and milk and its products as these all food groups are available in the study area and socially and culturally accepted in their respective communities.

\section{CONCLUSIONS}

Food choice behavior of the households is a complex process influenced by a variety of determinants related to the food like environmental and the economic factors of the household respondents which includes social, cultural and institutional issues in the study area. Food choice behavior of the households determines which nutrients and other substances enter the body and subsequently influence health, morbidity and mortality. The proportions of household respondents' food choice behavior categories show that the majority of the respondents (Both borderline and poor food choice behavior categories) were inadequate food choice behavior and were food insecure.

The analysis result of ordered logit model showed that total farm land holding, total number of livestock 
owned by the respondents in Tropical Livestock Unit (TLU), access to credit service, education level (EDULEVEL) of the household head, agro-ecology all have positively and significantly influence on the food choice behavior of rural households. While dependency ratio has negatively and significantly affects the food choice behavior of the rural households in the study area.

\section{RECOMMENDATIONS}

Based on the findings of this study the following recommendations are drawn:

Training should be given to provoke rural households towards the importance of diversifying different varieties of edible crops and worth eating for rural households of the study area. And Bore Agricultural research center (BOARC), which owned Guji Zone in general as a mandatory scope, should adapt different seed crops of different varieties based on the respective agro ecologies of the study area. Office of the agriculture and natural resources (BoANR) of the district should also takeover these technologies and scale up to popularize in the study area. This ensures the availability of different food crops and consecutively improves rural households' food choice behavior in the study area.

As insecure land tenure and policies that discourage benefits of small -scale livestock keepers can lead to the rapid loss of adequate food choice behavior, enabling small- scale livestock keepers, especially pastoralists/agropastoralists and indigenous people, to continue their livestock- keeping ways by providing secure and respecting their rights is very important.

Any local financial institutions should help in giving credit services to rural households and due attention should also be taken to train rural households in advance before giving credit to aware rural households how and what to do with the money.

It is important to convey accurate and consistent messages through various media, on food packages and of course via health extension workers at local health post and to train rural households to develop skill of meal preparation.

Bore Agricultural research center (BOARC) should adapt and demonstrate different edible crop varieties based on their traits to the three agro- ecologies to ensure crop diversity and the availability of various food items and enhance adequate food choice behavior of the study area. Agricultural and natural resource office of the District (BoANR) should also takeover these technologies for further popularization and reach at each door of the rural households in the study area. Advice should also be given by health personals to integrate different diets in their daily meals.

enhancing efficient delivery of training by local GOs and NGOs to aware the importance of family planning and convincing rural households in the study area is crucial for adequate food choice behavior and for the overall social and economic development of the family as insufficient nutrients and energy can lead to decreased productivity, disease, and death and thus exacerbate poverty.

\section{ACKNOWLEDGMENT}

The author would like to gratitude Oromia Agricultural Research Institute (OARI), for financial support. The staff of Bureau of Agriculture and Natural Resource (BoANR) of Adola Rede district where the study conducted, and 150 household respondents, key informants and focus groups for their concern in devoting their precious time during the interview to make my research work successful.

\section{REFERENCES}

Christine E. Blake. 2014. Understanding drivers of food choice in diverse and dynamic settings: Conceptual and methodological innovations.

De Almeida MDV, et al. 1997. Sources used and trusted by nationally-representative adults in the European Union for information on healthy eating. European Journal of Clinical Nutrition 51:S8-15.

Drewnowski, A. 2004. "Obesity and the food environment: dietary energy density and diet costs", American Journal of Preventive Medicine, 27, 154-62.

FAO 1996. Rome Declaration on World Food Security and World Food Summit Plan of Action. World Food Summit, 13-17 November 1996, Rome.

FAO 2006. The State of Food Insecurity in the World.

Greene, W.H., 2000. Economic Analysis. 4th edition, Prentice-hall, Inc. Upper Saddlee River, New Jersy.

Gujarati, D.N. 1995. Basic Econometrics 4th edition, McGraw Hill, New York.

Gujarati, D.N. 2004.Essential of Econometrics, 4th edition.Mc-Grew hill companies, 1003p.

Horjus, P., Kennedy, G., Berardo, A., Papavero,C., Ballard, T., Dop, M.Brouwer, I. A. 2010 Proxy measures of household food consumption for food security assessment and surveillance: comparison of household dietary diversity and food consumption scores. Public Health Nutrition, 13 (12), 2010-2018.

International Food and Research Institute 2014. Global Nutrition Report: Actions and Accountability to Accelerate the World's Progress on Nutrition. Washington, DC. 
Kearney, M., Kearney, J., Dunne, A., Gibney, M. 2000, "Sociodemographic determinants of perceived influences on food choice in a nationally representative sample of Irish adults", Public Health Nutrition, 3(2), 219-26.

Liao, T.F. 1994. Interpreting Probability Models: Logit, Probit, and Other Generalized Linear Models. Sage University Paper Series on Qualitative Applications in the Social Sciences.Thousand Oakes.CA; Sage.

Murcott A.1998. The Nation's Diet - The social Science of food choice. London: Longman. .

RK Oniang'o, JM Mutuku and SJ Malaba 2003. Contemporary African food habits and their nutritional and health implications, 12 (3): 231-236.

Storck, H., Bezabih Emana, Berhanu Adnew, A. Borowiccki and Shimelis W/Hawariat, 1991. Farming systems and resource economics in the tropics: farming system and farm management practices of smallholders in the Hararghe highland. Vol.11, Wissenschaftsverlag Vauk, Kiel, Germany.

Stubblefield et al. (2010); California Center for Rural Policy (CCRP).

Udayakumara, E. P., Shrestha, R. P., Samarakoon, L., and Schmidt-Vogt, D. 2010. People's perception and socioeconomic determinants of soil erosion: A case study of Samanalawewa watershed, Sri Lanka. International Journal of Sediment Research, 25(4): 323-339.

Vaitla, b., Tesfaye, G.mRounseville and Maxwell, D. 2012. Resillience and Livelihoods change in Tigray Ethiopia. Feinstein International Center, Tufts University.

WFP . 2008. Food Consumption Analysis: Calculation and use of the food consumption score in food security analysis.

WHO .2011. Obesity and Overweight. Fact sheet No. 311, Updated March 2011, Geneva.

\section{APPENDICES}

Table.2. Eight different aggregated food groups, from sixteen food groups of FAO food balance sheet and different weights, ranging from 0.5 to 4 , according to their nutrient density.

\begin{tabular}{|c|c|c|c|}
\hline No & $\begin{array}{l}\text { Food groups from FAO food balance } \\
\text { sheet }\end{array}$ & $\begin{array}{l}\text { Aggregated into eight food } \\
\text { groups }\end{array}$ & Weight values \\
\hline 1 & Cereals & \multirow[t]{2}{*}{ 1). Starches } & \multirow[t]{2}{*}{2} \\
\hline 2 & Roots and tubers & & \\
\hline 3 & Vitamins A rich vegetables and tubers & \multirow[t]{3}{*}{ 2). Vegetables } & \multirow[t]{3}{*}{1} \\
\hline 4 & dark green leafy vegetables & & \\
\hline 5 & other vegetables & & \\
\hline 6 & vitamin A rich fruits & \multirow[t]{2}{*}{ 3).Fruits } & \multirow[t]{2}{*}{1} \\
\hline 7 & other fruits & & \\
\hline 8 & organ meat & \multirow[t]{4}{*}{ 4). Meat } & \multirow[t]{4}{*}{4} \\
\hline 9 & flesh meats & & \\
\hline 10 & Eggs & & \\
\hline 11 & fish and sea food & & \\
\hline 12 & legumes, nuts and seeds & 5). Legumes & 3 \\
\hline 13 & milk and milk products & 6). Dairy & 4 \\
\hline 14 & oils and fats & 7). Fats & 0.5 \\
\hline 15 & Sweets & 8). Sweets & 0.5 \\
\hline 16 & spices, condiments, beverage & & 0 \\
\hline
\end{tabular}

Source: FAO, 2008 and Viatla et al., 2012 